\title{
CORRECTION
}

\section{Correction to: The effect of functional overreaching on parameters of autonomic heart rate regulation}

\author{
Clint R. Bellenger ${ }^{1,2} \cdot$ Rebecca L. Thomson ${ }^{1} \cdot$ Eileen Y. Robertson $^{2} \cdot$ Kade Davison $^{1} \cdot$ Maximillian J. Nelson $^{1}$. \\ Laura Karavirta $^{3}$. Jonathan D. Buckley ${ }^{1}$
}

Published online: 11 October 2018

(c) Springer-Verlag GmbH Germany, part of Springer Nature 2018

\section{Correction to: Eur J Appl Physiol (2017) 117:541-550}

https://doi.org/10.1007/s00421-017-3549-5

The original version of this article unfortunately contained a mistake. The presentation of Equation was incorrect.

The equation should read as:

$C=\frac{2 \cdot c \cdot \mathbf{e}}{c+\mathbf{e}}$.

The original article can be found online at https://doi.org/10.1007/ s00421-017-3549-5.

Clint R. Bellenger

clint.bellenger@mymail.unisa.edu.au

1 Alliance for Research in Exercise, Nutrition and Activity (ARENA), Sansom Institute for Health Research, University of South Australia, 2471, Adelaide, SA 5001, Australia

2 South Australian Sports Institute, Adelaide, Australia

3 Polar Electro Oy, Kempele, Finland 